\title{
VALORES, SOCIALIZAÇÃO E COMPORTAMENTO: SUGESTÕES PARA UMA SOCIOLOGIA DA ELITE JUDICIÁRIA
}

\author{
Renato M. Perissinotto
}

Pedro Leonardo Medeiros

Rafael T. Wowk

\section{RESUMO}

Este artigo propõe estratégias de pesquisa que contribuam para uma Sociologia das Elites Judiciárias. Para tanto, defende a necessidade de articular pesquisas que, ao mesmo tempo, identifiquem os valores professados pelos agentes jurídicos, analisem as instituições no interior das quais tais agentes são socializadas e, por fim, estudem as suas decisões. Na sua primeira parte, o artigo apresenta os resultados de um questionário aplicado aos desembargadores do Tribunal de Justiça do Paraná, no ano de 2006, no que diz respeito aos seus valores jurídicos. A segunda parte faz considerações sobre a necessidade de estudar os processos de socializações exógena e endógena dos entrevistados para que se possa entender algumas das respostas analisadas no item anterior. Por fim, defende-se, a necessidade de um estudo comportamental desses agentes por meio de pesquisas quantitativas e qualitativas de suas decisões (acórdãos). O artigo não pretende produzir conclusões definitivas, dado o caráter ainda inicial de algumas de nossas pesquisas.

PALAVRAS-CHAVE: elite judiciária; Tribunal de Justiça do Paraná; valores jurídicos.

\section{INTRODUÇÃO}

Tomar como objeto de análise científica o ato de julgar dos magistrados - neste caso particular, o dos desembargadores do Tribunal de Justiça do Estado do Paraná (TJ-PR) - implica romper com certo senso comum que enxerga na figura do Juiz um mero "aplicador da lei", agente passivo e inteiramente submetido aos protocolos de conduta do mundo jurídico. Lembrar que os juízes não são autômatos a executar uma programação de forma alguma significa fazer a apologia, mais ou menos envergonhada, da liberdade do "sujeito" ante as instituições: os magistrados, como quaisquer outros agentes sociais - e isto é um pressuposto sociológico e não uma hipótese -, não são "livres"; ou melhor, não possuem um leque de possibilidades igualmente prováveis de ação.

Se é inegável que os juízes estão submetidos aos constrangimentos institucionais do poder Judiciário (como leis, regimentos internos, jurisprudências etc.), e que estes influem em suas decisões, também não se pode ignorar que, como agentes dotados de uma determinada trajetória social, os magistrados carregam para a sua atuação profissional um conjunto de valores adquirido ao longo de sua formação e de sua carreira. Desse modo, no momento em que a formalização da conduta dos operadores jurídicos mostrar-se-ia mais frágil, abrindo algumas brechas para a "in- terpretação da lei”, surgiria não um sujeito livre de determinações, mas um agente portador de crenças e valores que, muito provavelmente, afetariam o sentido daquela "interpretação". Entendemos, portanto, que é o conjunto de valores e crenças - adquirido tanto nas escolas de Direito como ao longo da própria atividade profissional - que intermedeia a relação dos magistrados com os constrangimentos institucionais. Em outras palavras, acreditamos que a relação entre os agentes e as "regras do jogo" jamais é imediata ou direta, mas mediada por toda a trajetória anterior de tais agentes, trajetória esta que se faz necessário analisar ${ }^{1}$.

Foi essa problemática que motivou a realização, no ano de 2006, de um conjunto de entrevistas com uma amostra dos desembargadores do

\footnotetext{
1 Adotando-se, portanto, o pressuposto daquilo que a literatura americana sobre as decisões da Suprema Corte chama de "modelo atitudinal”: "Contra o modelo legalista, apresentamos o modelo atitudinal, que defende que a justiça toma decisões considerando os fatos à luz de seus valores e atitudes ideológicos”. (SEGAL \& SPAETH, 2002, p. 110). Evidentemente, como lembram os autores, trata-se de um "modelo" que, enquanto tal, não exclui outras determinações (legais e racionais, por exemplo) das decisões judiciais. Para uma revisão da literatura americana sobre os modelos explicativos das decisões judiciais, cf. Koerner (2007).
} 
TJ-PR. Por meio de questionário, aplicado a 71 dos 120 magistrados (não muito longe, portanto, de nosso objetivo amostral de 84 desembargadores), coletamos informações sobre as seguintes variáveis: dados pessoais; origem social; trajetória escolar; carreira profissional; valores jurídicos, políticos e sociais; atividade acadêmica e intelectual; participação e associativismo $^{2}$. Essa pesquisa, por sua vez, incentivou o surgimento de outros dois estudos, um sobre a natureza das decisões produzidas no processo judicante pelos entrevistados e outro sobre o processo de socialização desses agentes. Exceto a aplicação do survey a que nos referimos anteriormente, todas essas outras pesquisas estão ainda em andamento.

O objetivo deste artigo, portanto, não é apresentar conclusões finais. Na verdade, pretendemos utilizar algumas de nossas estratégias de pesquisa e alguns dos dados produzidos até o presente momento para defender uma proposta no que diz respeito ao estudo da elite judiciária ${ }^{3}$. Como pode-se perceber por um contato mesmo superficial com a literatura sociológica sobre o poder Judiciário no Brasil, há um número cada vez maior de estudos demográficos sobre os operadores jurídicos, nos quais predominam a preocupação com a identificação da origem social, do gênero, do nível de renda, da trajetória profissional, enfim, dos "atributos adstritos e adquiridos" (KELLER, 1971) que caracterizam os entrevistados. Ao contrário, há uma ausência quase absoluta (salvo algumas poucas exceções) de análises das instituições nas quais os operadores jurídicos são socializados e não menos escassos são os estudos acerca das decisões produzidas por esses agentes ${ }^{4}$.

2 O banco de dados completo encontra-se disponível no Consórcio de Informações Sociais (CIS) da Associação Nacional de Pós-Graduação e Pesquisa em Ciências Sociais (Anpocs) (cf. CASTRO et alii, 2006).

3 Acreditamos, inclusive, que as sugestões de pesquisa esboçadas neste artigo podem ser aplicadas ao estudo das mais diversas elites sociais e políticas.

4 Depois do predomínio de uma sociologia jurídica feita por profissionais do campo do direito, apareceram no Brasil alguns trabalhos pioneiros, cujo objetivo era apresentar uma descrição quantitativa rigorosa e exaustiva de alguns atributos dos membros da magistratura brasileira. Nesse caso, merecem destaque os trabalhos de Vianna et alli (1996; 1997). Seguindo o mesmo tipo de abordagem, podemos citar os trabalhos de Sadek (1995; 2006) e Junqueira, Vieira
Este artigo pretende defender a indissolubilidade entre três tipos de pesquisa sociológica nos estudos sobre as elites, em geral, e sobre as elites judiciárias, em particular. A nosso ver, é fundamental, num primeiro momento, mapear os valores do grupo a ser analisado por meio da aplicação de um survey, tomando-se como plausível a hipótese de que as condutas são, na maioria das vezes, normativamente orientadas; em seguida, é preciso perguntar-se onde tais valores foram adquiridos, com vistas a recuperar o "trabalho pedagógico" por meio do qual as estruturas de socialização são interiorizadas pelos agentes ${ }^{5}$. Por fim, somente um estudo comportamental (no caso, decisional) permitiria demonstrar (ou não) a eficácia do processo de socialização, revelando-se, ao mesmo tempo, a intensidade e a freqüência com que as condutas são de fato orientadas pelos valores identificados na primeira etapa da investigação. Infelizmente, as pesquisas que nos forneceram alguns dados para elaborar esse artigo não foram pensadas de maneira integrada. O que pretendemos, portanto, é tão somente sugerir como um estudo das elites judiciárias teria muito a ganhar com um desenho de pesquisa que procurasse integrar esses três tipos de abordagem (dos valores, da socialização e do comportamento).

Nesse sentido, este artigo está dividido em três partes. Na primeira delas, descrevemos os valores jurídicos detectados pela aplicação do nosso questionário aos desembargadores do Tribunal de Justiça do Paraná, em 2006. Em seguida, discutimos a necessidade de fazer-se uma sociologia dos processos exógenos e endógenos de socialização dos entrevistados, supondo-se ter o primeiro ocorrido no interior de duas instituições escolares estratégicas (etapa que nomeamos como "socializa-

e Fonseca (1997). Alguns outros pesquisadores adotaram uma perspectiva mais qualitativa em seus estudos, em geral lançando mão dos instrumentos analíticos da sociologia de Pierre Bourdieu e preocupados em identificar os processos de socialização que contribuíram para a autonomização do campo jurídico no Brasil, como, por exemplo, Bonelli (2002) e Engelman (2001a; 2001b; 2006). Com relação às análises de decisões judiciais, cf. Ericeira (1994), Portanova (1997) e Rosa (2004). Para uma revisão mais extensa de parte dessa literatura, cf. Perissinotto (2008).

5 O “trabalho pedagógico" é entendido como um modo de inculcação - implícito ou explícito - de um determinado habitus. Enquanto tal, engloba o aprendizado pedagógico formal, mas não se reduz a ele (cf. BOURDIEU \& PASSERON, 1992, p. 57). 
ção jurídica primária”), e o segundo, ao longo de suas atividades profissionais como operadores jurídicos, seja como magistrados, como promotores públicos ou advogados ${ }^{6}$. Na última parte, apresentamos o que poderia ser visto como uma proposta para o estudo das decisões produzidas por esses agentes, com vistas a averiguar em que medida tais decisões são afetadas (se é que são) por condicionantes jurídicos e extrajurídicos. Por fim, à guisa de conclusão, sintetizamos os pontos centrais de nossas considerações.

\section{OS VALORES JURÍDICOS DOS DESEMBAR- GADORES}

A eficácia simbólica do discurso jurídico reside, ao menos em parte, na coerência interna de suas proposições, coerência que o diferencia, por exemplo, dos atos arbitrários e forçosamente parciais dos indivíduos singulares. Se, como defende Bourdieu (1989, p. 216), o "espírito jurídico" consiste justamente nesta postura universalizante, torna-se compreensível que a existência de sistemas de normas jurídicas concorrentes esteja, por definição, vetada (ao menos dentro de uma mesma unidade de jurisdição). Um discurso jurídico, a fim de impor-se como tal, precisa apresentar-se como uma dedução necessária dos textos da lei, ou seja, como conseqüência lógica de um conjunto de proposições universalmente reconhecidas.

Quem sabe seja por este fato - o de o mundo jurídico possuir a lógica da universalidade como princípio de funcionamento - que o declínio do paradigma normativo-formalista, com o conseqüente aumento do pluralismo nas tendências jurídicas, seja elencado como um dos sintomas da chamada "crise do poder Judiciário", que nada mais seria, segundo Werneck Vianna et alli (1997, p. 12), do que a difícil adaptação desse poder da República à nova conjuntura nacional surgida $\mathrm{a}$ partir da redemocratização e da promulgação da Constituição de 1988.

Ora, é preciso, antes de mais nada, lembrar que o mundo jurídico não se constitui num bloco monolítico ou num "aparelho", unidade de tal modo racionalizada que não deixaria qualquer espaço a conflitos, mas num "lugar de concorrên-

6 Quanto a essas duas dimensões do processo de socialização (externa e interna), cf., por exemplo, Carp e Stidham (2001, p. 272-279). cia pelo direito de dizer o direito" (BOURDIEU, 1989, p. 212), lugar onde se opõe diferentes classes de agentes e instituições: advogados, juízes, promotores públicos, juristas, professores, tribunais estaduais, federais, faculdades etc., cada um deles animado pelo interesse específico associado à sua posição no campo, bem como por uma visão particular do Direito. Obviamente, a necessidade de manter o princípio da universalidade, com o recurso ao cânone jurídico, constitui-se num limite severo para esta concorrência entre os agentes, assim como impede que o conflito de interpretações se transforme numa ameaça à legitimidade ou ao reconhecimento dos textos da lei e, conseqüentemente, de seus "intérpretes"”. Tal oscilação entre as inovações oriundas da concorrência entre os agentes do campo e o necessário trabalho de racionalização e sistematização, sem o qual o Direito perderia sua coerência interna mínima, parece explicar, por exemplo, a ambigüidade que todo código de leis comporta, a despeito do esforço dos teóricos - Kelsen, em particular de fazer do Direito um sistema auto-suficiente e, de sua "interpretação", uma "ciência positiva”.

A ambigüidade dos códigos, justamente o princípio do "espaço de jogo” à disposição dos "intérpretes”, pode ser vista, nessa perspectiva, como a acomodação dos diferentes interesses e orientações, não apenas das diferentes corporações jurídicas, mas também dos diferentes grupos de elite em concorrência. Tal ambigüidade fica ainda mais clara, como chama a atenção Werneck Vianna et alli, no caso das constituições posteriores à II Guerra Mundial, em que foram introduzidos princípios normativos de legitimidade absoluta - como uma concepção do "justo" ou da "dignidade humana” - que servem como fonte obrigatória de limitação ao Direito Positivo, em um claro enfraquecimento da oposição entre este e o Direito Natural (idem, 1997, p. 24-25).

Como parte desta tendência do constitucionalismo moderno - a de acomodar um maior número de interesses e orientações, ao preço de um aumento da ambigüidade e da incoerência - a

\footnotetext{
7 O apego à estabilidade e à previsibilidade jurídicas, mesmo por parte daqueles que defendem uma relação, por assim dizer, mais criativa com o direito, é um dos aspectos responsáveis pelo ritmo pianíssimo das mudanças no interior do campo jurídico. Com relação a este ponto, cf. Bancaud (1989).
} 
Constituição Federal de 1988 também deu lugar a um processo de "positivação do direito natural"8, com um conseqüente aumento do "espaço de jogo" e da potencialidade discricionária da atividade jurisdicional. Este maior espaço para as estratégias de argumentação somado à transformação das relações entre os poderes da República e destes com a sociedade civil, estaria, ainda segundo Werneck Vianna et alli, no princípio de uma "desneutralização" ou "politização" do poder Judiciário, instado, a partir de então, a assumir um novo papel na dinâmica social (idem, p. 27).

\section{II.1. O que pensam os desembargadores sobre o papel do poder Judiciário}

É esta preocupação com a transformação do papel e da posição do Judiciário, bem como com seu reflexo no pensamento e na prática dos magistrados brasileiros, que tem motivado as pesquisas a respeito dos valores destes agentes, das quais Corpo e alma da magistratura brasileira (WERNECK VIANNA et alli,1997) e Magistrados: uma imagem em movimento (SADEK, 2006) constituem destaques. Uma das questões comuns a estes trabalhos é justamente a do grau de adesão, por parte dos juízes, ao paradigma normativoformalista ou, ao contrário, a uma orientação mais afeta às implicações de ordem social e econômica das decisões, com referência, por vezes, aos princípios gerais de "justiça social” e "dignidade humana”.

No questionário aplicado aos desembargadores do TJ-PR, também nos preocupamos em reservar uma parte das questões para a indagação dos valores jurídicos destes agentes, em especial quanto aos temas da função e da autonomia do Judiciário na sociedade brasileira atual. Inspirados nas pesquisas acima mencionadas, procuramos mapear a visão dos magistrados a respeito do Direito e da atividade jurídica, em especial quanto às alternativas de uma orientação centrada na "certeza jurídica”, com uma estrita observância aos precedentes jurídicos, ou, ao contrário, na "justiça social”, princípio abstrato impulsionador de uma atitude supostamente mais disposta aos desvios criativos em relação à jurisprudência.

\section{QUADRO 1 - QUAL DEVE SER O PAPEL DO PODER JUDICIÁRIO?}

\begin{tabular}{|l|cc|}
\hline OPINIÃO SOBRE O PAPEL DO JUDICIÁRIO & $\boldsymbol{N}$ & 吅 \\
\hline Função ético-moral de educador da sociedade para a cidadania & 15 & 21,1 \\
Limitar-se a dirimir conflitos entre indivíduos ou gnupos & 10 & 14,1 \\
Deve promover a realizaçẫo plena do Estado de Direito & 46 & 64,8 \\
Total & 71 & 100,0 \\
\hline
\end{tabular}

FONTE: Castro et alii (2006).

A fim de mapear os valores jurídicos dos desembargadores, começamos por indagá-los a respeito do papel do Judiciário em face à sociedade brasileira, dando-lhes um conjunto de alternativas, já utilizadas em Corpo e alma da magistra-

\footnotetext{
8 A Constituição federal de 1988 expandiu as disposições sobre o “justo”, a “dignidade humana” etc. Exemplo disto são os fundamentos da República Federativa do Brasil previstos no art. $1^{\circ}$ da Constituição, entre eles a cidadania, a dignidade da pessoa humana e os valores sociais do trabalho e da livre iniciativa. Estas disposições - juntamente com a função social da propriedade - são tidas à primeira vista como meras normas “programáticas”, mas, na verdade, são essenciais para a hermenêutica constitucional e geram amplo debate jurídico, inclusive tornando inconstitucionais - mediante declaração judicial - disposições infraconstitucionais (entre elas, as leis).
}

tura brasileira, que vão de uma posição marcadamente não-intervencionista ("o poder Judiciário deve limitar-se a intervir quando mobilizado por indivíduos ou grupos em conflito em torno de um bem juridicamente tutelado") ao seu oposto ("o poder Judiciário deve atribuir-se um papel ético-moral na sociedade, educando-a para a vida pública e a cidadania”), passando por uma posição intermediária ("o poder Judiciário deve promover a realização plena do Estado de Direito, garantindo a aplicação da lei e sua correta interpretação”). Como em Corpo e alma, a maior freqüência foi registrada na posição intermediária (64,8\%), enquanto a opção marcadamente intervencionista e o seu contrário ficaram em $21,1 \%$ e $14,1 \%$, respectivamente (naquela pesquisa, seguindo a mesma ordem, os valores ficaram em $74,8 \%, 14,6 \%$ e $10,6 \%$ ). 
De modo coerente com a percepção acerca do papel do poder Judiciário, os desembargadores adotam uma compreensão sobre a sua atuação profissional que nem os reduz a meros aplicadores dos códigos ("o Desembargador, assim como todo Juiz, é um aplicador imparcial da lei e, portanto, não cabe a ele perseguir a implementação de princípios éticos, morais e políticos exteriores ao direito, mas sim a certeza jurídica), nem os conduz a abandonar a "estrita observância da lei” (“a atuação profissional do Desembargador deve se pautar pela busca da justiça social e pelo atendimento das reivindicações de sujeitos coletivos, mesmo que para isso tenha que romper com a estrita observância da lei”). Desse modo, incentivados a identificar qual deve ser o princípio norteador de sua atuação profissional, a grande maioria (78,9\%) optou por uma resposta intermediária, em que se aceita a intromissão, no ato de julgar, de princípios éticos, morais e políticos exteriores ao direito (tais como a justiça social, a cidadania etc.), desde que submetidos ao respeito à lei ("princípios éticos, morais e políticos exteriores ao direito, tais como a justiça social, a cidadania etc., devem ser perseguidos pelo Desembargador no exercício de sua atividade profissional desde que isso não implique romper com a estrita observância da lei”). As posições extremadas (o Juiz como paladino da justiça social à revelia do direito e o Juiz como mero garantidor da certeza jurídica) receberam adesão bem menor.

A diferença fundamental entre essas tomadas de posição é, evidentemente, a idéia de "estrita observância da lei”. Parece-nos que ela serve bem como um indicador do grau de adesão do Desembargador ao marco da "certeza jurídica". Em Magistrados, uma imagem em movimento (SADEK, 2006), optou-se, ao contrário, por abordar a questão dos valores jurídicos sem apelar a dicotomias ou a uma contraposição entre as diferentes posições. No capítulo de Joaquim Falcão (2006), "O múltiplo Judiciário", presente no livro, há, inclusive, uma crítica às pesquisas que fazem uso de uma demarcação clara entre "certeza jurídica” e "justiça social”, pois estas partiriam, segundo o autor, de uma visão "irrealista" e de uma "incompreensão do processo decisório dos juízes” (idem, p. 132-133). Pensamos, contudo, que o mérito de questões dicotômicas é justamente o de obrigar os respondentes a se situarem entre pólos contrários, que, como tais, serão necessariamente "irrealistas", no sentido em que o são, por exemplo, os tipos ideais weberianos.

O objetivo, assim, não é extrair dos agentes uma descrição realista de suas práticas (o que só o cientista, ao fim da pesquisa, poderá estabelecer), mas obter respostas necessariamente extremadas (ou mesmo caricaturais) que, em sua parcialidade, denunciem uma certa hierarquia de valores ou esquemas mentais e possibilitem a construção de classificações. O sentido exato das respostas obtidas através de um questionário fechado, entretanto, só pode ser auferido por meio de pesquisas qualitativas (etnografia, entrevista em profundidade etc.), pesquisas cujas diretrizes serão dadas justamente pelas tendências denunciadas na etapa quantitativa.

Os dados apresentados até este momento mostram claramente que as maiores freqüências foram registradas nas alternativas que representam posições intermediárias do espectro de valores jurídicos, com o restante das respostas dividindo-se entre os dois pólos opostos, um caracterizado por termos como "certeza jurídica” e "neutralidade" e outro, por termos como "justiça social" e "cidadania”, com uma ligeira vantagem para este último. A realização plena do Estado de Direito $(\mathrm{N}=46)$ e a busca de princípios éticos, morais e políticos exteriores ao cânone jurídico, desde que sem ruptura com a estrita observância da lei $(\mathrm{N}=56)$, foram as opções que mais atraíram os desembargadores, sendo que 38 deles, em uma amostra de 71, concordaram com ambas.

Tais dados estão em concordância com os obtidos por Werneck Vianna et alli (1997, p. 258263) e sugerem que o aumento do pluralismo no espaço das tomadas de posição teóricas a respeito do Direito não foi capaz de desintegrar o núcleo comum ao redor do qual as visões alternativas orbitam. Embora as tomadas de posição ligadas à idéia de "justiça social”, “cidadania” e "redução das desigualdades” pareçam ter um poder cada vez maior de atração sobre a magistratura, a "realização plena do Estado de Direito" e a "fiel interpretação da lei” continuam balizando o espaço mental do mundo jurídico ${ }^{9}$. Nesse sentido, compreende-se que a grande maioria dos desembargadores entre-

\footnotetext{
9 Apesar de a comparação ser prejudicada por conta das diferenças metodológicas, os dados sobre valores jurídicos apresentados por Sadek (2006, p. 47-49) também sugerem um crescimento da atenção à "justiça social” (83,8\% dos
} 
vistados $(76,1 \%)$ concordem com a proposição segundo a qual "o direito positivo brasileiro é suficiente para solucionar os conflitos que se apresentam ao TJ”. Por sua vez, é também compreensível que, dentre os 14 respondentes que se declararam insatisfeitos, a proporção da recusa ao paradigma da "certeza jurídica" e de defesa da "justiça social”, mesmo que ao preço da "estrita observância à lei”, seja maior do que entre os satisfeitos, o que sugere uma ligação entre orientações mais afastadas do padrão normativo-formalista e sentimentos de insatisfação quanto ao Direito em vigor, ligação que poderia estar relacionada, por exemplo, a um comportamento mais propenso aos desvios criativos em relação aos precedentes jurídicos.

\section{II.2. O que pensam os desembargadores sobre a autonomia do Judiciário e da magistratura}

Se o espaço das tomadas de posição teóricas a respeito da função do Direito e do poder Judiciário admite alguma pluralidade de orientações - fato compreensível desde que tratemos o mundo jurídico não como um "aparelho", mas como um lugar de concorrência entre diferentes tipos de interesses e disposições jurídicas -, o mesmo não pode ser dito a respeito das questões relativas à autonomia da magistratura. Aqui, vê-se como a concorrência entre diferentes concepções teóricas pode encobrir um amplo consenso quanto aos aspectos práticos de regulamentação e controle da atividade profissional da corporação.

\section{QUADRO 2 - QUALA MELHOR FORMA DE RECRUTAR OS MEMBROS DO PODER JUDICIÁRIO?}

\begin{tabular}{|c|c|c|}
\hline MODO DE RECRUTAMENTO & N. & 吆 \\
\hline Juizes eleitos garantem o aprimoramento da democracia & 1 & 1,4 \\
\hline Concursos públicos sã̃o mais democráticos e universais & 70 & 98,6 \\
\hline Total & 71 & 100,0 \\
\hline
\end{tabular}

FONTE: Castro et alii (2006).

Quando instados a responder sobre a melhor forma de recrutamento dos magistrados, a esmagadora maioria dos desembargadores $(98,6 \%)$ optou pela proposição “o Estado Democrático de Direito é melhor assegurado pelo sistema de concurso público para ingresso na magistratura, evitando a intromissão das diversas formas de particularismo no exercício da justiça”, no mais amplo consenso registrado em nosso questionário; apenas um Desembargador optou pela proposição "a existência de juízes eleitos garantiria ao poder Judiciário uma proximidade efetiva com os valores da comunidade, traduzindo-se em aprimoramento da ordem democrática”.

Tal consenso em torno da instituição do concurso público se estende provavelmente por toda a magistratura ${ }^{10}$, já que encarna com perfeição

magistrados na ativa, segundo esta pesquisa, concordam que se deve ter "compromisso com as conseqüências sociais" das decisões, contra $64,1 \%$ dos aposentados; no caso dos magistrados com até 5 anos de carreira, a porcentagem sobe para 90,2\%).

10 Os dados de Werneck Vianna et alii (1997, p. 296) sobre o tema, embora coletados há mais de dez anos, são também os ideais de universalidade e imparcialidade que caracterizam a representação social a respeito de toda burocracia. A eleição como forma de recrutamento, ao estabelecer inevitavelmente uma relação de representação (ou ao menos a suspeita dela), parece tocar num ponto de honra dos magistrados: a independência em relação ao jogo político. Os dados de Sadek (2006, p. 49-56) mostram claramente, por exemplo, a avaliação negativa que a magistratura faz do Supremo Tribunal Federal (STF) no que se refere à independência deste em relação ao poder Executivo; a forma atual de composição do STF, com a indicação sendo feita pelo Presidente da República e aprovada pela maioria absoluta do Senado, aparece, igualmente, como amplamente reprovada - a opção de restringir o processo de indicação apenas à corporação, ao contrário, é a que conta com maior aprovação ${ }^{11}$.

bastante expressivos: 88\% dos magistrados entrevistados concordava em algum grau com o recrutamento por concurso público.

11 A fim de ilustrar ainda mais este ponto de honra dos juízes brasileiros que é a independência em relação às forças do campo político, basta atentar a outro dado apresentado 
É preciso lembrar ainda que a opção pela eleição como modo de recrutamento para a carreira, em detrimento do concurso, representaria a perda, por parte da corporação, do monopólio sobre os instrumentos de reprodução de seu corpo, já que, atualmente, para o nosso objeto de estudo, o processo seletivo é realizado pelo próprio Tribunal de Justiça, sendo a comissão do concurso responsável, inclusive, pela avaliação na prova oral - formada por desembargadores e por um advogado. Evidentemente, o processo seletivo é também uma forma de garantir um nível mínimo de competência técnica, assim como uma certa homogeneização que não seria possível, ou seria bem menor, por meio de eleições.

Essa valorização da autonomia da corporação é claramente reforçada pelas opiniões acerca da existência de um controle externo sobre o poder Judiciário. Indagados a respeito da opção com a qual mais concordavam em relação ao problema do controle externo sobre o poder Judiciário, $57,7 \%$ dos desembargadores entrevistados defenderam a posição de que não deve existir controle externo sobre a magistratura, numa inequívoca rejeição a quaisquer mecanismos de constrangimento sobre os magistrados. A opção “o controle externo ao poder Judiciário deve ser exercido por um órgão composto por magistrados, membros do Ministério Público e representantes da OAB [Ordem dos Advogados do Brasil]" recebeu o apoio de $33,8 \%$ dos entrevistados, contra 5,6\% da opção "o controle externo deve ser exercido por um órgão composto por representantes dos três poderes"; finalmente, a proposição "o controle externo deve ser exercido por representantes das organizações da sociedade civil” recebeu a adesão de apenas dois desembargadores, ou seja, de 2,8\% da amostra.

Os dados mostram claramente a opção dos entrevistados por uma magistratura livre de mecanismos de controle, numa aversão que cresce à medida que tais mecanismos afastam-se do universo burocrático e estatal: um órgão composto por agentes do campo jurídico é mais aceito, pelos desembargadores da amostra, do que um formado por representantes dos demais poderes; e

por Sadek (2006, p. 57): 86\% dos entrevistados refuta a participação político-partidária de magistrados, contra apenas $9 \%$ favoráveis a ela. ambos são preferíveis em relação a um constituído por elementos da sociedade civil. Deduzimos disso que os entrevistados percebem o corpo de magistrados como capaz de arbitrar e resolver os conflitos e problemas que se lhe apresentam, sem necessidade, portanto, de recorrer a forças externas ao campo jurídico ou mesmo à corporação dos juízes, numa afirmação inconteste do "espírito de corpo" deste grupo, para além das divergências professadas em matéria de tomadas de posição teóricas.

\section{A PRODUÇÃO DAS CRENÇAS E DOS VA- LORES JURÍDICOS DOS DESEMBARGA- DORES: SOCIALIZAÇÕES EXÓGENA E ENDÓGENA}

\section{III.1. Socialização exógena: as escolas de Direito e a socialização jurídica primária dos desembargadores}

Nenhum estudo de elites estará completo se não somar, ao mapeamento dos sistemas de valores e dos padrões comportamentais, uma análise específica sobre o processo social de produção dos membros destas elites. Em outras palavras, é preciso ir além da mera descrição dos atributos de um grupo (religião, orientação política, profissão, status etc.) a fim de mostrar como estas propriedades - as quais um estudo sincrônico registra - foram-lhe de fato transmitidas. Para isso, é necessário tomar como objeto de análise os mecanismos de socialização e reprodução por meio dos quais os diferentes grupos transmitem suas heranças (econômicas e culturais) e dentro dos quais a família e a escola desempenham um papel preponderante. É, portanto, o processo de produção social do habitus dos desembargadores que devemos enfocar se não quisermos nos limitar a um estudo substancialista de seus atributos.

Muito embora a socialização intra corporis tenha certamente um peso considerável na produção das disposições dos desembargadores e, por este intermédio, em seus votos nos processos, gostaríamos de chamar a atenção, num primeiro momento, para as escolas de Direito, pois as consideramos lugares privilegiados de observação do processo pelo qual não apenas os magistrados, mas também advogados, promotores e juristas são produzidos. Por serem a porta de entrada ao mundo jurídico, as escolas são responsáveis pelos primeiros contatos sistemáticos com os temas, pro- 
blemáticas, linguagens e interesses do campo ${ }^{12}$. Será, além disso, sobre esta "socialização jurídica primária” que a profissionalização dentro de de- terminada carreira irá agir, da mesma forma como o trabalho pedagógico da escola só pode incidir sobre disposições já formadas no seio familiar.

QUADRO 3 - INSTITUIÇÕES EM QUE OS DESEMBARGADORES FORMARAM-SE

\begin{tabular}{|l|c|c|}
\hline \multicolumn{1}{|c|}{ INSTITUIÇÃ́O } & $N$ & $\%$ \\
Faculdade de Direito da Alta Paulista & 1 & 1,4 \\
Faculdade de Direito de Maringá & 1 & 1,4 \\
Faculdade de Direito do Vale do Paraíba & 1 & 1,4 \\
Faculdade de Direito de Curitiba & 22 & 31,0 \\
Instituto Toledo de Ensino & 1 & 1,4 \\
PUC-PR & 9 & 12,7 \\
UEL & 5 & 7,0 \\
UEM & 3 & 4,2 \\
UEPG & 1 & 1,4 \\
UFPR & 26 & 36,6 \\
PUC-RJ & 1 & 1,4 \\
Total & 71 & 100,0 \\
\hline
\end{tabular}

FONTE: Castro et alii (2006).

NOTA: PUC-PR: Pontifícia Universidade Católica do Paraná; UEL: Universidade Estadual de Londrina; UEM: Universidade Estadual de Londrina; UEPG: Universidade Estadual de Ponta Grossa; UFPR: Universidade Federal do Paraná; PUC-RJ: Pontifícia Universidade Católica do Rio de Janeiro.

A centralidade das escolas no conjunto dos mecanismos de socialização dos desembargadores aumenta se levarmos em conta que apenas duas instituições (Faculdade de Direito Curitiba e UFPR) foram responsáveis pela formação de 46 dos 71 entrevistados (67,6\%). Nos parece perfeitamente plausível, portanto, transformar as tendências encontradas na etapa quantitativa da pesquisa (mapeamento das propriedades dos agentes) em diretrizes e hipóteses a serem operacionalizadas num estudo a respeito destas duas instituições centrais do campo jurídico paranaense.

\footnotetext{
12 Em famílias com tradição jurídica, o contato com as coisas do Direito é, certamente, mais precoce, mas mesmo assim não pode ser comparado ao processo sistemático de socialização que somente a escola é capaz de promover. Essa afirmação é ainda mais verdadeira para o nosso caso, pois, ao contrário do que apregoa o senso comum, os desembargadores entrevistados não são, na sua grande maioria, oriundos de famílias jurídicas. Apenas $26,1 \%$ deles foram explicitamente incentivados pela família a seguir a carreira jurídica e somente $14,1 \%$ tinham o pai atuando no campo jurídico.
}

Entre outras questões, é preciso relacionar os consensos e dissensos que encontramos entre os desembargadores - em matéria de orientação jurídica, de organização da carreira, de relação com a política - ao trabalho pedagógico ao qual estes foram submetidos em suas graduações. Um estudo desse tipo deve necessariamente levar em conta não apenas as diferenças entre as instituições, mas também entre as diferentes épocas de ingresso no curso, variante fundamental no caso de nossa amostra, em que bacharéis formados em 1962 convivem com outros formados já na década de 1980. Não há como reconstruir este trabalho pedagógico e este processo geral de socialização ao qual os desembargadores, então estudantes de Direito, foram submetidos, sem produzir, por exemplo, uma história comparada dos currículos ou sem analisar os sistemas de avaliação, que, como sugere Bourdieu (1974, p. 207), "indicam com alguma defasagem as questões que orientaram e organizaram o pensamento de uma época”, ou, ainda, sem avaliar o peso concedido a cada disciplina ou área do Direito - Público ou Privado, Direito Civil ou do Trabalho, Teoria Geral do 
Estado ou Sociologia do Direito - pelas instituições formadoras. Todos esses aspectos são facetas a serem exploradas por uma história do trabalho pedagógico ${ }^{13}$.

Pela configuração das relações de força implícitas aos currículos, poderíamos ter idéia do peso, por exemplo, da "certeza jurídica” e do paradigma normativo-formalista ou, ao contrário, da "justiça social" e de paradigmas mais abertos às ciências históricas e sociais. Seria preciso, ainda, contrapor o resultado de um estudo deste tipo à percepção dos próprios desembargadores a respeito de suas formações, como indicam os dados do quadro 4.

QUADRO 4 - QUAL PRINCÍPIO A SUA GRADUAÇÃO ENFATIZOU?

\begin{tabular}{|l|c|c|}
\hline PRINCíPIO ENFATIZADO & $\begin{array}{c}\text { FACULDADE DE DIREITO } \\
\text { DE CURITIBA }\end{array}$ & UFPR \\
\hline $\begin{array}{l}\text { Visẫo do direito ligada à cidadania e à justiça } \\
\text { social } \\
\begin{array}{l}\text { o profissional do Direito deve se ater } \\
\text { estritamente ao texto da lei }\end{array}\end{array}$ & $16(72,7 \%)$ & $19(73,1 \%)$ \\
Total & $6(27,3 \%)$ & $7(26,9 \%)$ \\
\hline
\end{tabular}

FONTE: Castro et alii (2006).

Os dados do quadro não mostram diferença significativa na avaliação das duas escolas, mas ao compararmos as opiniões dos desembargadores formados em cada uma delas, algumas tendências aparecem. Por exemplo, diante da proposição "a emergência de novos sujeitos sociais vem inaugurando lugares e procedimentos que estão desempenhando funções substitutivas às do Judiciário; a democracia ganha mais com a difusão de vias paralelas ao poder Judiciário do que com sua expansão”, a proporção de adesão entre os formados na Faculdade de Direito Curitiba (FDC) e na UFPR foi praticamente inversa: $36,4 \%$ entre os formados na primeira e $61,5 \%$ entre os da segunda. No que diz respeito ao papel do poder Judiciário, o percentual de respondentes da FDC que defende que este deve se limitar a dirimir conflitos entre os indivíduos privados $(23,8 \%)$ é o dobro dos formados pela UFPR (11,5\%) que optaram pela mesma resposta; também representa o dobro o percentual dos formados pela FDC $(14,3 \%)$, em relação ao percentual dos formados pela UFPR $(7,7 \%)$, que

13 A literatura sobre o ensino jurídico nacional divide-se, basicamente, entre aquela voltada para questões políticopedagógicas (como a série “OAB, Ensino Jurídico”) e outra que se concentra numa história geral do estabelecimento e desenvolvimento dos cursos de Direito (VENÂNCIO FILHO, 1977), ou, ainda, que procura relacionar o ensino jurídico e a cultura política nacional (ADORNO, 1988). concordaram fortemente com a afirmação de que o direito positivo brasileiro é suficiente para resolver os conflitos que se apresentam ao TJ.

Não podemos, obviamente, sobretudo em função do caráter sincrônico dos nossos dados, estabelecer uma relação de causalidade entre essas duas variáveis (escola de formação e orientação normativa). No entanto, as "coincidências" elencadas acima sugerem certamente uma diretriz para a pesquisa qualitativa, única capaz de responder de forma satisfatória às questões que a etapa quantitativa nos interpõe.

\section{III.2. Socialização endógena: a produção interna} do ethos dos desembargadores

No caso de elites profissionais, como os desembargadores aqui estudados, soma-se ainda a necessidade de atentar à socialização intra corporis, ou seja, à profissionalização, entendida como incorporação de capacidades, ao mesmo tempo técnicas e sociais, exigidas por determinada carreira ou atividade. No caso da magistratura, estas exigências vão desde o domínio sobre o cânone jurídico legado pela tradição do campo cabedal de conhecimentos que diferencia o especialista do leigo - até a adequação postural e lingüística, sem a qual não haveria suficiente distinção entre os juízos autorizados do magistrado e as opiniões parciais e necessariamente interessadas das partes em confronto. Com relação a esse ponto, vale atentar para o fato de que o tempo 
médio de carreira dos desembargadores entrevistados ${ }^{14}$ é de quase 29 anos, tempo suficientemente longo para que ocorra, se for o caso, um processo de socialização eficiente e a formação de um ethos adequado ao tipo de atividade exigida no campo em questão.

Uma forma de tangenciar os prováveis efeitos desse longo período de trajetória profissional até chegar ao TJ-PR é analisar a percepção que os magistrados de carreira têm daqueles desembargadores oriundos do mundo exterior à magistratura e a visão que esses mesmos magistrados de carreira têm de si próprios.
Como se sabe, há duas formas de ingresso nos Tribunais de Justiça: uma reservada aos magistrados de carreira, com alternância entre os critérios de antiguidade e merecimento, e outra, conhecida como Quinto Constitucional ${ }^{15}$, aberta aos membros do Ministério Público e aos advogados. Por constituir-se numa "entrada lateral” ao principal Tribunal da Justiça estadual, o Quinto representa um tema privilegiado para captar as relações entre as diferentes corporações do mundo jurídico. Em nosso questionário, perguntamos aos desembargadores como eles se posicionavam diante deste mecanismo institucional.

\section{QUADRO 5 - OPINIÃO SOBRE O QUINTO CONSTITUCIONAL}

\begin{tabular}{|l|c|c|}
\hline OPINIÃO SOBRE O QUINTO & $\boldsymbol{N}$ & $\%$ \\
\hline É importante pela contribuiçẫo dos promotores e adrogados & 33 & 46,5 \\
O TJ deve ser formado apenas por magistrados de carreira & 38 & 53,5 \\
Total & 71 & 100,0 \\
\hline
\end{tabular}

FONTE: Castro et alii (2006).

Pouco mais da metade dos entrevistados (53,5\%) optou pela proposição "o TJ funcionaria melhor se fosse formado integralmente por magistrados de carreira, pois estes estão acostumados com a prática judicante desde o início de sua vida profissional, sendo, portanto, melhor treinados para o ato de julgar”; a proposição favorável ao Quinto, “o Quinto Constitucional é importante porque com ele os promotores e advogados trazem a contribuição de suas experiências profissionais, arejando a prática judicante dentro do TJ”, contou com a adesão de $46,5 \%$ da amostra.

Se avaliarmos apenas as respostas dos magistrados de carreira entrevistados, veremos que a oposição ao Quinto sobe para 63,8\%, enquanto entre os demais desembargadores, vindos da advocacia e do Ministério Público, ela é de apenas 7,7\% (curiosamente, um Desembargador oriundo do Quinto posicionou-se contra este mecanismo). A rejeição, demonstrada pelos magistrados de carreira, é alta se pensarmos que ela tem como

\footnotetext{
14 O tempo médio de carreira foi contado a partir do início das atividades do entrevistado na magistratura, para os magistrados de carreira, no Ministério Público e na advocacia, para os que ingressaram pelo Quinto Constitucional, até a entrada no TJ-PR.
}

objeto não agentes oriundos de campos sociais diversos, mas agentes do campo jurídico - detentores, portanto, do título de bacharel em Direito, assim como os magistrados de carreira. Ao que parece, a participação no "espírito de corpo" constitutivo do grupo dos desembargadores exige algo mais que a pertinência ou a familiaridade em relação ao mundo jurídico: faz-se necessário, também, um processo de socialização (e de consagração) específico à carreira, processo que se inicia com a aprovação no concurso e que culmina, depois da passagem pelas diversas entrâncias, com a eleição, pelos próprios desembargadores, para o Tribunal de Justiça.

Para captar de forma mais precisa este "espírito de corpo", pedimos aos entrevistados que dissessem quais as três características, por ordem de importância, mais distintivas dos desembargadores. A idéia, aqui, era mapear o tipo

\footnotetext{
15 Segundo o Art. 94 da Constituição Federal, um quinto dos lugares nos tribunais de Justiça e tribunais Regionais Federais devem ser reservados aos membros do Ministério Público e aos advogados. A escolha é feita pelo Governador do Estado, que seleciona um nome dentre três previamente selecionados pelas associações das carreiras - OAB, no caso dos advogados, e Associação do Ministério Público (AMP), no caso dos promotores.
} 
de representação social que este grupo tem a respeito de si mesmo, o que pode dizer muito, pen- samos, sobre a relação que mantêm com o mundo jurídico em geral.

\begin{tabular}{|c|c|c|c|}
\hline \multirow{2}{*}{$\begin{array}{l}\text { HIERARQUIA DAS } \\
\text { ALTERNATINAS }\end{array}$} & \multicolumn{3}{|c|}{ HIERARQUIAS DAS RESPOSTAS } \\
\hline & $1^{\circ}$ LUGAR & $2^{\circ}$ LUGAR & $3^{\circ}$ LUGAR \\
\hline $\begin{array}{l}\text { Primeira característica } \\
\text { mais importante }\end{array}$ & $\begin{array}{c}\text { Trabalhadores } \\
(21,1 \%)\end{array}$ & $\begin{array}{l}\text { Íntegros } \\
(18,3 \%)\end{array}$ & $\begin{array}{l}\text { Sóbrios, fomais, equilibrados } \\
\qquad(14.1 \%)\end{array}$ \\
\hline $\begin{array}{l}\text { Segunda característica } \\
\text { mais importante }\end{array}$ & $\begin{array}{l}\text { Competentes } \\
\qquad(25,4 \%)\end{array}$ & $\begin{array}{c}\text { Trabalhadores } \\
(14,1 \%)\end{array}$ & $\begin{array}{l}\text { Íntegros } \\
(14,1 \%)\end{array}$ \\
\hline $\begin{array}{l}\text { Terceira característica } \\
\text { mais importante }\end{array}$ & $\begin{array}{c}\text { Trabalhadores } \\
(15,5 \%)\end{array}$ & $\begin{array}{l}\text { Íntegros } \\
(11,3 \%)\end{array}$ & $\begin{array}{l}\text { Preoc upados com a justiça social } \\
\qquad(9,9 \%)\end{array}$ \\
\hline
\end{tabular}

FONTE: Castro et alii (2006).

No quadro acima, apresentamos apenas as características que obtiveram maior presença no conjunto de respostas a três questões que pretendiam hierarquizar as características distintivas de um Desembargador, segundo eles próprios. Podemos observar que o adjetivo "trabalhadores", além de ser o mais citado como primeira característica definidora dos desembargadores, é também aquele que mais aparece se somarmos os resultados das três questões $(\mathrm{N}=36)$. Tal dado parece estar de acordo com a percepção corrente a respeito da sobrecarga de trabalho da magistratura em geral, fator apontado como parte da "crise do Judiciário"16.

Vale observar que, com relação a esse ponto, os desembargadores encontram-se em uma situação que bem poderia ser descrita pelo conceito de "ambivalência sociológica" (MERTON, 1979) ${ }^{17}$. Nela, vivenciam uma forte tensão entre, por um lado, a necessidade de "julgar com pres-

16 Cf. Sadek (2006, p. 32): 48,9\% dos entrevistados avaliaram como "ruim” a agilidade do poder Judiciário.

17 Com o conceito de “ambivalência sociológica” Merton descreve a existência de uma tensão gerada pelas exigências funcionais de um papel social que constrangem o ator com imposições normativas contraditórias. No caso dos desembargadores, espera-se deles que atendam a uma demanda social cada vez maior e espera-se também que o façam com respeito às características necessariamente morosas do ato de julgar. A ambivalência sociológica, inscrita no nível da estrutura social (i. e., dos papéis sociais e das sa” e, por outro, as exigências operacionais e éticas do ato de julgar. Ora, julgar, por definição, exige atenção, leitura rigorosa do processo, consulta aos códigos, enfim, trata-se de um ato demorado. No entanto, o aumento vertiginoso das demandas colocadas à Justiça obriga os desembargadores a apressar esse processo, constituindo-se essa contradição numa das mais importantes fontes de tensão da profissão. Esta percepção negativa a respeito das próprias condições de trabalho, no entanto, parece reverter-se, entre os desembargadores, como vimos pelos dados acima, numa avaliação positiva a respeito de si mesmos ("trabalhadores") e, muito provavelmente, num fator de coesão e solidariedade entre o grupo, reforçando justamente aquilo que chamamos o "espírito de corpo".

A característica “íntegros” aparece também em todas as hierarquizações, sendo a segunda mais citada na primeira e na terceira delas; o mesmo acontece com "compromissados com a justiça/ imparcialidade", muito embora em freqüência marcadamente menor. O adjetivo "competentes”,

expectativas a eles vinculadas) pode, como lembra Merton, traduzir-se em tensão psicológica (cf. MERTON, 1979, p. 20-21). As informações acerca dessa ambivalência entre os desembargadores foram retiradas de observações diretas feitas por pesquisadores do Núcleo de Pesquisa em Sociologia Política Brasileira, entre os dias 12 de maio e 6 de junho de 2005. 
por sua vez, reuniu $25,4 \%$ das respostas à pergunta "qual a segunda característica mais definidora dos desembargadores?” e 12,7\% em relação à primeira característica definidora. $\mathrm{O}$ único atributo inequivocamente negativo a aparecer em nossas respostas foi o de "distantes/incompetentes”, embora com uma freqüência modesta $(\mathrm{N}=4)$.

Outro dado que nos parece bastante interessante é a presença, logo na primeira hierarquia de características, do grupo de adjetivos afins "sóbrios, formais, equilibrados, educados e atenciosos”, que ilustram bem aquilo que Bourdieu (1989, p. 227) chama de habitus jurídico: "as atitudes ao mesmo tempo ascéticas e aristocráticas, que são a realização incorporada do dever de reserva, são constantemente lembradas e reforçadas pelo grupo dos pares, sempre pronto a condenar e a censurar os que se comprometeriam de modo demasiado aberto com questões de dinheiro ou de política”. A postura universalizante, parte deste habitus específico que é o do mundo jurídico, implica, ao que parece, uma distância neutralizante em relação aos interesses apaixonados das partes em conflito, distância que pode ser vista, segundo o observador, de forma positiva, como "sobriedade e equilíbrio", ou, negativamente, como "conservadorismo e distanciamento em relação às causas sociais”, características, todas elas, presentes em nossos dados.

Essa percepção que os desembargadores têm de si mesmo como trabalhadores e íntegros revela, porém, um viés imposto pelo amplo predomínio numérico, entre os entrevistados, de desembargadores que são magistrados de carreira. Como se percebe pela tabela abaixo, essa mesma percepção se repete quando os entrevistados são instados a identificar a principal característica de um Juiz, mas percepções bem distintas aparecem quando se trata de revelar quais são, para eles, os traços definidores dos promotores públicos e dos advogados.

QUADRO 7 - PRIMEIRA CARACTERÍSTICA DEFINIDORA DO JUIZ, DO PROMOTOR PÚBLICO E DO

\begin{tabular}{|c|c|c|c|}
\hline \multirow[t]{2}{*}{ CATEGORIA } & \multicolumn{3}{|c|}{ CARACTERÍSTICAS MAIS IMPORTANTES } \\
\hline & $1^{0}$ LUGAR & $2^{\circ}$ LUGAR & $3^{\circ}$ LUGAR \\
\hline Juiz & $\begin{array}{c}\text { Trabalhadores } \\
(20,6 \%)\end{array}$ & $\begin{array}{l}\text { Competentes } \\
(16,2 \%)\end{array}$ & $\begin{array}{l}\text { Íntegros } \\
(13,2 \%)\end{array}$ \\
\hline $\begin{array}{l}\text { Promotor } \\
\text { público }\end{array}$ & $\begin{array}{c}\text { Corajosos e combativos } \\
(16,4 \%)\end{array}$ & $\begin{array}{c}\text { Trabalhadores } \\
(11,5 \%)\end{array}$ & $\begin{array}{l}\text { Íntegros } \\
(9,8 \%)\end{array}$ \\
\hline Advogado & $\begin{array}{c}\text { Competentes } \\
(16,9 \%)\end{array}$ & $\begin{array}{l}\text { Despreparados e incompetentes } \\
\qquad(15,4 \%)\end{array}$ & $\begin{array}{c}\text { Trabalhadores } \\
\quad(15,4 \%)\end{array}$ \\
\hline
\end{tabular}

FONTE: Castro et alii (2006).

Como, em função da própria composição do TJ, há um predomínio numérico muito grande de desembargadores oriundos da magistratura, é compreensível que as características mais citadas para qualificar um Desembargador se repitam na caracterização dos juízes em geral. Desse modo, também são vistos como fundamentalmente trabalhadores, competentes e íntegros. Por sua vez, as características definidoras dos promotores e

\footnotetext{
18 Neste caso apresentamos apenas as três características mais citadas como a principal característica que define um juiz, um promotor público e um advogado. Não há, portanto, como na tabela anterior, referências à segunda e à terceira características mais importantes.
}

dos advogados, na visão de um grupo no qual predominam juízes de carreira, são bem diferentes. Os promotores são vistos principalmente como corajosos e combativos, o que descreveria adequadamente o lugar que o Ministério Público ocupa no campo jurídico, como instituição dedicada a defender o "interesse público" e a combater os "interesses espúrios”. Os advogados, porém, são definidos de forma totalmente contraditória. Quase na mesma proporção, são vistos tanto como competentes quanto como incompetentes e despreparados, o que talvez expresse adequadamente o desnível na qualidade dos cursos de Direito, em função da proliferação de cursos de graduação nessa área nos últimos anos. 
De qualquer modo, vale insistir que há um certo padrão nessas percepções, na medida em que adjetivos distintos são aplicados a categorias profissionais distintas. Nesse sentido, essas formas de classificação de si próprios (os juízes) e dos outros (advogados e promotores) pode ser o indício de um ethos profissional moldado por processos de socialização intra corporis.

\section{COMO OS DESEMBARGADORES JULGAM}

Um dos pontos mais delicados para as pretensões científicas da Sociologia reside na sua capacidade de desenvolver procedimentos que consigam revelar, ao menos em alguma medida, relações causais entre processos de socialização, valores manifestos e comportamentos observáveis. No caso específico da Sociologia da elite judiciária, acreditamos que um estudo comportamental, isto é, das decisões produzidas pelos seus agentes, pode ser um caminho frutífero para a realização de tal objetivo. Com relação a este ponto, ainda não temos dados que possam ser apresentados nem sequer de forma razoavelmente sistematizada. No entanto, acreditamos que vale a pena apresentar ao leitor o desenho da pesquisa em andamento e as questões de trabalho que servem de fio condutor para a sua realização.

Dois importantes estudos norte-americanos serviram de inspiração para essa parte de nossa pesquisa, a saber, os artigos de Steffensmeier e Hebert (1999) e Steffensmeier e Britt (2001). Ambos os trabalhos lançam mão de uma metodologia comum e de um mesmo banco de dados. A preocupação fundamental desses autores é saber se há alguma correlação entre o perfil dos julgadores, o perfil dos julgados e a decisão. Do ponto de vista do perfil dos decisores e do perfil dos réus, os autores trabalham com as variáveis "gênero" e "raça". A questão central da pesquisa é saber se a raça e o gênero dos juízes afetam as suas decisões, levando-se em conta também a raça e o gênero dos réus. Para ser mais claro, trata-se de saber em que medida um juiz negro é mais ou menos benevolente frente a um réu negro e em que medida uma juíza é mais ou menos benevolente com criminosos que cometeram crimes contra as mulheres. Nos dos artigos, as correlações entre essas variáveis e as decisões existem, mas não são significativas (sobretudo no que diz respeito à raça), o que leva os autores a defenderam a proposição de que as decisões são condicionadas sobretudo por razões de ordem le- gal e institucional. Ou seja, as decisões sofreriam o impacto muito mais da socialização interna do que da socialização externa (i. e., a trajetória do juiz como negro ou branco; como homem ou mulher).

Para montarmos o nosso banco de dados, partimos da análise de dois tipos de crime distintos do ponto de vista do capital que exigiriam para serem cometidos. Ou seja, de um lado, os crimes de furto, que praticamente dispensam a posse de qualquer capital; de outro, crimes como peculato e corrupção, que exigem capital social, econômico e político para que possam ser cometidos $^{19}$. Cada um desses crimes tem, como se sabe, penas que variam de um mínimo a um máximo legalmente fixado. Dentro dessa escala, a pena efetivamente aplicada pelo Desembargador depende de uma série de outras variáveis legais e de circunstâncias que permitem caracterizar melhor o ato cometido pelo réu. Portanto, não há, nesses casos, uma aplicação mecânica da lei, na qual teríamos, para os mesmos crimes, sempre a mesma decisão. Desse modo, a extensão das penas varia, ainda que dentro de limites legalmente fixados. O nosso objetivo consiste exatamente em identificar as causas dessa variação.

Para tanto, perguntamo-nos se há alguma relação explicativa entre o perfil do Desembargador responsável pela decisão (no caso, tomamos apenas a decisão do relator $)^{20}$, o perfil do réu, o tipo de crime cometido e a pena. Para o perfil dos desembargadores foram utilizados os dados coletados pelo questionário descrito na primeira parte deste artigo, em especial as informações relativas à raça, sexo, idade, religião (se é ou não praticante), instituição em que se graduou (FDC ou UFPR) e trajetória profissional (se é ou não magistrado de carreira). Para o perfil do réu fo-

19 O banco de dados contém 173 entradas. Cada auto ("processo") pode dar origem a mais de uma entrada, pois, em casos de concurso de agentes, individualizamos os réus, e, em casos de concurso material (crimes diferentes cometidos por ações/omissões diversas, tendo em comum apenas o agente), individualizamos os crimes. Dessas entradas, 57 são de processos de crimes que exigem capital social e 116 de crime de furto.

20 O que não representa nenhum problema para a pesquisa, dado o baixo número de divergência entre os desembargadores. A decisão nos tribunais de segundo grau, como o TJ-PR, é, em regra, colegiada, feita por um Desembargador (ou Juiz substituto em segundo grau) relator, um revisor e um vogal. Em apenas oito dos 173 casos $(4,6 \%)$ analisados houve divergência de votos. 
ram utilizados os dados encontrados no próprio processo, tais como raça, gênero, religião, antecedentes criminais, profissão, renda e escolaridade. Por fim, pretendemos fazer uma análise qualitativa dos acórdãos produzidos para os casos analisados. Acreditamos que se alguma relação há entre os valores identificados pela aplicação do questionário, os processos de socialização externos e internos e as condutas dos desembargadores no momento de julgar, essa relação poderá ser identificada por meio desta pesquisa ainda em andamento.

\section{CONSIDERAÇÕES FINAIS}

Como dissemos no início deste artigo, o nosso objetivo não era apresentar conclusões já que as pesquisas descritas neste texto não foram pensadas de maneira integrada e algumas delas se encontram ainda em andamento. Ainda assim, acreditamos que os dados preliminares aqui apresentados ao menos autorizam algumas de nossas proposições, apresentadas na forma de hipóteses de trabalho.

O mais importante, entretanto, reside, a nosso ver, na proposta teórica que motivou a elaboração deste texto. Os estudos sobre elites, em especial aqueles dedicados às elites políticas, têm sido muito criticados por se limitarem ao mapeamento do perfil dos integrantes dos grupos analisados, sem que se desenvolva, ao mesmo tempo, uma análise comportamental para averiguar em que medida os atributos (sociais, econômicos, culturais e políticos) de um dado grupo afetam (se afetam) o seu comportamento.
A nosso ver, não há por que reduzir os estudos das elites aos aspectos comportamentais. No entanto, é inegável que se as trajetórias sociais dos indivíduos e os atributos que eles adquirem ao percorrê-las têm algum significado sociológico, este significado deve estar ligado, em alguma medida e de algum modo, ao comportamento adotado por eles. Deve-se supor, do ponto de vista sociológico, que se os indivíduos de um dado grupo são portadores do mesmo habitus, então é provável que eles adotem o mesmo comportamento frente a situações sociais semelhantes.

Acreditamos que para revelar as conexões existentes entre esses aspectos é preciso lançar mão de diferentes estratégias de pesquisa. Por essa razão, defendemos que é de fundamental importância conjugar as pesquisas quantitativas, permitidas pela aplicação de questionários fechados ou por meio do preenchimento de fichas prosopográficas, com análises qualitativas e históricas. No caso específico da elite judiciária estudada neste artigo, pensamos que a análise quantitativa permite mapear os valores manifestos dos desembargadores entrevistados e, no futuro, tornará possível captar um padrão decisional nos seus julgamentos. Por sua vez, as análises históricas e qualitativas permitirão recuperar a história das instituições nas quais esses indivíduos foram socializados e produzir uma abordagem verticalizada (por exemplo, por meio da análise do discurso) dos textos que compõem os acórdãos produzidos pelo Tribunal de Justiça do Paraná.

Renato Monseff Perissinotto (monseff@uol.com.br) é Doutor em Ciências Sociais pela Universidade Estadual de Campinas (Unicamp), Professor Adjunto do Departamento de Ciências Sociais da Universidade Federal do Paraná (UFPR) e Pesquisador do Conselho Nacional de Desenvolvimento Científico e Tecnológico (CNPq).

Pedro Leonardo Medeiros (pedroleocm@uol.com.br) é Graduando em Ciências Sociais pela Universidade Federal do Paraná (UFPR) e Bolsista de Iniciação Científica do Conselho Nacional de Desenvolvimento Científico e Tecnológico (CNPq).

Rafael Taraszkiewicz Wowk (rtwowk@ufpr.br) é Graduando em Ciências Sociais pela Universidade Federal do Paraná (UFPR) e Bolsista de Iniciação Científica do Conselho Nacional de Desenvolvimento Científico e Tecnológico (CNPq).

\section{REFERÊNCIAS BIBLIOGRÁFICAS}

ADORNO, S. 1988. Os aprendizes do poder : o bacharelismo liberal na política brasileira. Rio de Janeiro : Paz e Terra.
BANCAUD, A. 1989. Une “constance móbile” : la haute magistrature. Actes de la recherce em science sociales, Paris, v. 76-77, p. 30-48, mars. 
BONELLI, M. 2002. Profissionalismo e política no mundo do Direito : as relações dos advogados, desembargadores, procuradores de justiça e delegados de polícia com o Estado. São Carlos : FAPESP.

BOURDIEU, P. 1974. Sistemas de ensino e sistemas de pensamento. In : A economia das trocas simbólicas. São Paulo : Perspectiva.

1989. A força do Direito : elementos para uma Sociologia do Campo Jurídico. In : O poder simbólico. Lisboa : B. Brasil.

BOURDIEU, P. \& PASSERON, J.-C. 1992. A reprodução : elementos para uma teoria do sistema de ensino. Rio de Janeiro : F. Alves.

CARP, R. \& STIDHAM, R. 2001. Judicial Process in America. Washington, D. C. : CQ.

CASTRO, L. F.; POLATTI, R.; WOWK, R. T. \& PERISSINOTTO, R. M. 2006. Quem são e o que pensam os Desembargadores do Tribunal de Justiça do Estado do Paraná, 2006. Banco de dados B273. Disponível em : http:// w w w. n a d d.pr p . u s p.br/cis / DetalheItem.aspx?cod=B273. Acesso em: 15.mar.2008.

ENGELMAN, F. 2001a. A formação da elite jurídica no Rio Grande do Sul. Porto Alegre. Dissertação (Mestrado em Ciência Política). Universidade Federal do Rio Grande do Sul.

2001b. A trajetória do corpo docente da Faculdade de Direito de Porto Alegre/UFRGS e a definição do espaço jurídico no Rio Grande do Sul. Passo Fundo : s/n.

2006. Sociologia do Campo Jurídico : juristas e usos do Direito. Porto Alegre : Fabris.

ERICEIRA, J. B. 1994. Como decidem os juízes no estado do Maranhão. São Luís : UFMA.

FALCÃO, J. 2006. O múltiplo Judiciário. In : SADEK, M. T. (org.). Magistrados : uma imagem em movimento. Rio de Janeiro : FGV.

JUNQUEIRA, E. B.; VIEIRA, J. R. \& FONSECA, M. G. P. 1997. Juízes : retrato em preto e branco. Rio de Janeiro : Letra Capital.

KELLER, S. 1971. Mas allá de la clase dirigente. Madrid : Tecnos.
KOERNER, A. 2007. Instituições, decisão judicial e análise do pensamento jurídico : o debate norte-americano. BIB, Rio de Janeiro, n. 63, p. 63-96.

MERTON, R. 1979. A ambivalência sociológica e outros ensaios. Rio de Janeiro : Zahar.

PERISSINOTTO, R. M. 2008. "Vocação inata” e recursos sócio-culturais : o caso dos desembargadores do Tribunal de Justiça do Paraná. Direito, Estado e Sociedade, Rio de Janeiro, n. 31, p. 175-198, jul.-dez.

PORTANOVA, R. 1997. Motivações ideológicas da sentença. $3^{\text {a }}$ ed. Porto Alegre : Livraria do Advogado.

ROSA, A. M. 2004. Decisão no processo penal como bricolage de significantes. Curitiba. Tese (Doutorado em Direito). Universidade Federal do Paraná.

SADEK, M. T. (org.). 1995. Uma introdução ao estudo da justiça. São Paulo : Sumaré.

2006. Magistrados : uma imagem em movimento. Rio de Janeiro : FGV.

SEGAL, J. A. \& SPAETH, H. J. 2002. The Supreme Court and the Attitudinal Model Revisited. Cambridge : Cambridge University.

STEFFENSMEIER, D. \& BRITT, C. L. 2001. Judges' Race and Judicial Decision Making : Do Black Judges Sentence Differently? Social Science Quarterly, v. 82, n. 4, p. 749-764, Dec.

STEFFENSMEIER, D. \& HERBERT, C. 1999. Women and Men Policymakers : Does the Judge's Gender Affect the Sentencing of Criminal Defendants? Social Forces, v. 77, n. 3, p. 1163-1196, Mar.

VENÂNCIO FILHO, A. 1977. Das arcadas ao bacharelismo : 150 anos de ensino jurídico no Brasil. São Paulo : Perspectiva.

WERNECK VIANNA, L. W.; CARVALHO, M. A. R.; MELO, M. P. C. \& BURGOS, M. B. 1996. O perfil do magistrado brasileiro. Rio de Janeiro : IUPERJ.

1997. Corpo e alma da magistratura brasileira. Rio de Janeiro : Revan. 
VALUES, SOCIALIZATION AND BEHAVIOR: SUGGESTIONS FOR A SOCIOLOGY OF THE JUDICIARY ELITE

\author{
Renato M. Perissinotto, Pedro Leonardo Medeiros, Rafael T. Wowk
}

This article proposes strategies for research that contributes to a Sociology of Judiciary Elites. For these purposes, it advocates the need to articulate research that identifies the professed values of juridical agents and analyzes the institutions within which these agents are socialized while going on to study their decisions. The first part of this article, we present results of a questionnaire that we applied to Paraná State (Tribunal de Justiça do Paraná) court judges, during the year 2006, regarding their juridical values. The second part makes some considerations on the need to study our interviewees' exogenous and endogenous socialization processes, in order to be able to understand some of responses we analyzed in the previous section. Finally, we advocate the need for behavioral study of these agents through qualitative and quantitative study of their decisions. The article does not intend to offer definitive conclusions, given the still preliminary nature of some of our research.

KEYWORDS: judiciary elite; Tribunal de Justiça do Paraná; juridical values.

\title{
VALEURS, SOCIALISATION ET COMPORTEMENT: SUGGESTIONS POUR UNE SOCIOLOGIE DE L'ÉLITE JUDICIAIRE
}

\section{Renato M. Perissinotto, Pedro Leonardo Medeiros, Rafael T. Wowk}

Cet article propose des stratégies de recherche qui puissent contribuer à une Sociologie des Élites Judiciaires. Il préconise donc la nécessité d'articuler les recherches qui, en même temps, identifient les valeurs prônées par les agents juridiques, analysent les institutions dans lesquelles ces agents sont socialisées et, finalement, étudient leurs décisions. Dans la première partie, l'article présente les résultats d'un questionnaire appliqué auprès des magistrats de la Cour de Justice du Paraná, en 2006, portant sur leurs valeurs juridiques. La deuxième partie discute de la nécessité d'étudier les processus de socialisation exogène et endogène des interrogés pour qu'on puisse comprendre certaines des réponses analysées précédemment. Enfin, on plaide la nécessite d'une étude comportementale de ces agents par l'intermédiaire de recherches quantitatives et qualitatives sur leurs décisions (jugements) L'article n'a pas l'intention de produire des conclusions définitives, compte tenu du caractère primaire de certaines de nos recherches.

MOTS-CLÉS: élite judiciaire; Cour de Justice du Paraná; valeurs juridiques. 